\title{
Total nut, tree nut, peanut, and peanut butter intake and the risk of prostate cancer in the Netherlands Cohort Study
}

Citation for published version (APA):

Boudewijns, E. A., Nieuwenhuis, L., Geybels, M. S., \& van den Brandt, P. A. (2019). Total nut, tree nut, peanut, and peanut butter intake and the risk of prostate cancer in the Netherlands Cohort Study. Prostate Cancer and Prostatic Diseases, 22(3), 467-474. https://doi.org/10.1038/s41391-019-0131-8

Document status and date:

Published: 01/09/2019

DOI:

10.1038/s41391-019-0131-8

Document Version:

Accepted author manuscript (Peer reviewed / editorial board version)

Document license:

CC BY-NC-ND

Please check the document version of this publication:

- A submitted manuscript is the version of the article upon submission and before peer-review. There can be important differences between the submitted version and the official published version of record.

People interested in the research are advised to contact the author for the final version of the publication, or visit the DOI to the publisher's website.

- The final author version and the galley proof are versions of the publication after peer review.

- The final published version features the final layout of the paper including the volume, issue and page numbers.

Link to publication

\footnotetext{
General rights rights.

- You may freely distribute the URL identifying the publication in the public portal. please follow below link for the End User Agreement:

www.umlib.nl/taverne-license

Take down policy

If you believe that this document breaches copyright please contact us at:

repository@maastrichtuniversity.nl

providing details and we will investigate your claim.
}

Copyright and moral rights for the publications made accessible in the public portal are retained by the authors and/or other copyright owners and it is a condition of accessing publications that users recognise and abide by the legal requirements associated with these

- Users may download and print one copy of any publication from the public portal for the purpose of private study or research.

- You may not further distribute the material or use it for any profit-making activity or commercial gain

If the publication is distributed under the terms of Article $25 \mathrm{fa}$ of the Dutch Copyright Act, indicated by the "Taverne" license above, 
Total nut, tree nut, peanut, and peanut butter intake and the risk of prostate cancer in the Netherlands Cohort Study

Esther A Boudewijns ${ }^{1,2}$ MSc, Lisette Nieuwenhuis ${ }^{1}$ MSc, Milan S Geybels ${ }^{3}$ PhD, Piet A van den Brandt ${ }^{1,3} \mathrm{PhD}$

1 Care and Public Health Research Institute (CAPHRI), Department of Epidemiology, Maastricht University Medical Center+, Maastricht, the Netherlands

${ }^{2}$ Care and Public Health Research Institute (CAPHRI), Department of Family Medicine, Maastricht University Medical Center+, Maastricht, the Netherlands

${ }^{3}$ GROW - School for Oncology and Developmental Biology, Department of Epidemiology, Maastricht University Medical Center+, Maastricht, the Netherlands

Corresponding author: Lisette Nieuwenhuis,

Department of Epidemiology, Maastricht University Medical Center+

P.O. Box 616, 6200 MD Maastricht, the Netherlands

Phone: +3143-3882902, Fax: +31-43388-4128

1.nieuwenhuis@maastrichtuniversity.nl

Running title: Nut intake and prostate cancer risk

Financial support: This study was funded by the Dutch Cancer Society (grant number UM 2015- 18 7860)

Word count (incl. abstract): 2846 


\section{Abstract}

Background: The consumption of nuts has been associated with a reduction of cancer risk, but only a few studies have examined the effects of nuts on prostate cancer risk. The current study prospectively investigated the association between the consumption of total nuts, tree nuts, peanuts, and peanut butter and the risk of total, advanced, and non-advanced prostate cancer. Methods: The association between nuts and prostate cancer was evaluated in the Netherlands Cohort Study, which was conducted among 58279 men aged 55-69 year at baseline. A casecohort approach was used for data processing and analyses. After 20.3 years of follow-up, 3868 incident prostate cancer cases and 1979 subcohort members were available for multivariable Cox regression analyses.

Results: For total, advanced, and non-advanced prostate cancer, no significant associations were found for total nuts (total prostate cancer: hazard ratio (HR) $(95 \% \mathrm{CI})$ for $10+\mathrm{g} /$ day vs. non-consumers $\left.=1.09(0.92-1.29), \mathrm{P}_{\text {trend }}=0.409\right)$. No significant associations were observed for tree nuts and peanuts for total, advanced, and non-advanced prostate cancer risk. Peanut butter consumption was associated with a significantly increased risk of non-advanced prostate cancer $\left(\mathrm{HR}(95 \% \mathrm{CI})\right.$ for $5+\mathrm{g} /$ day vs. non-consumers $=1.33(1.08-1.63), \mathrm{P}_{\text {trend }}=$ 0.008), but not with total or advanced prostate cancer.

Conclusions: No significant associations were found between total nut, tree nut, and peanut consumption and total, advanced, and non-advanced prostate cancer. Peanut butter might be associated with an increased non-advanced prostate cancer risk.

\section{Introduction}

Prostate cancer is the second most common cancer and the fifth leading cause of cancer death in men worldwide ${ }^{1}$. Several studies have investigated the association between etiological factors and prostate cancer risk, but the evidence has not been consistent ${ }^{2}$. This might be due 
to the heterogeneous nature of prostate cancer. Studies have indicated that risk factors for advanced and non-advanced prostate cancer differ, which can most likely be explained by the way they act on biological pathways ${ }^{3}$. Advanced prostate cancer cases have a higher diagnostic certainty, and often have stronger associations with etiological factors than nonadvanced prostate cancer cases. Non-advanced prostate cancer cases can therefore dilute the association towards the null if only total prostate cancer cases are investigated ${ }^{2,3}$. Three risk factors for prostate cancer have been well-established: age, ethnicity, and a positive family history of prostate cancer ${ }^{3,4}$. Potential risk factors for prostate cancer for which moderate to strong evidence from meta-analyses is available include body mass index (BMI) and height, and potential risk factors for which limited evidence is available include diabetes mellitus type 2, alcohol consumption, smoking, physical activity, and $\operatorname{diet}^{5-14}$, whereby the associations are often more pronounced for advanced than for non-advanced prostate cancer.

One food group that has a potential to reduce prostate cancer risk are nuts. Nut intake has consistently been associated with a reduction of several chronic conditions, including cancer risk and cancer-related mortality ${ }^{15-17}$. Although the exact mechanism is unclear, it is suggested that their beneficial impact relates to their antioxidant and anti-inflammatory properties ${ }^{18,19}$.

Only two prospective studies ${ }^{20,21}$ and three case-control studies ${ }^{22-24}$ have examined the association between the consumption of nuts and prostate cancer incidence or mortality. They show inconsistent results, demonstrating either a protective or a non-significant association. Moreover, studies that investigated the different effects on advanced and non-advanced prostate cancer risk are limited. The aim of the current study is to prospectively investigate the association between the consumption of total nuts, tree nuts, peanuts, and peanut butter, and the risk of total, advanced, and non-advanced prostate cancer. 


\section{Methods}

\section{Study design and population}

The current study was performed within the Netherlands Cohort Study (NLCS). The study started on 17 September 1986 and included 58279 men. A detailed description of the study is reported elsewhere ${ }^{25}$. For efficiency reasons, a case-cohort design was used, with cases derived from the entire cohort and the person-years at risk estimated in a subcohort. At baseline, participants consented to participate by completing and returning a mailed selfadministered questionnaire, including a 150-item semi-quantitative food frequency questionnaire (FFQ). A subcohort of 2411 men was randomly selected from the full cohort at the time of baseline measurement. Data on vital status was collected in the subcohort during the follow-up period of 20.3 years follow-up (until 31 December 2006), and was 100\% complete. Ethical clearance was obtained from the University Hospital Maastricht (Maastricht, the Netherlands) and the Netherlands Organisation for applied scientific research (TNO).

Data on incident prostate cancer cases in the entire cohort were collected using record linkage with the Netherlands Cancer Registry and the Dutch National Pathology Registry (PALGA) ${ }^{26}$. All cases were microscopically verified. The completeness of the cancer incidence follow-up was estimated to be at least $96 \%{ }^{27}$. Prostate cancer cases were classified using the guidelines of the International Union Against Cancer, with non-advanced prostate cancer cases classified as stage $\mathrm{T} 1$ or $\mathrm{T} 2$ and $\mathrm{N} 0$ and $\mathrm{M} 0$, and advanced prostate cancer cases classified as stage $\mathrm{T} 3$ or $\mathrm{T} 4, \mathrm{~N}+$, or $\mathrm{M} 1$. 
A flow diagram of the number of subcohort members and cases in the current study can be found in Figure 1. Cases and subcohort members with prevalent cancer (except for skin cancer) at baseline, with incomplete or inconsistent dietary data, or missing data on confounding variables were excluded from the analysis ${ }^{28}$. The study population in the current study includes 1979 subcohort members and 3868 incident prostate cancer cases diagnosed during the 20.3 years follow-up. Of these cases, 2329 were classified as non-advanced prostate cancer cases and 1256 as advanced prostate cancer cases. The classification for 283 cases was unclear.

\section{Exposure measurement}

The baseline questionnaire measured potential risk factors for cancers, including anthropometry, smoking habits, physical activity, and disease history. A validated FFQ assessed habitual diet in the preceding year ${ }^{28}$. The frequency of consumption of 'peanuts', 'other nuts, mixed nuts' (tree nuts), and 'peanut butter' was measured based on the following range: 'never or less than 1 time/month' to '6-7 times per week'. In addition, the number of standard portion sizes per intake was reported by participants. The standard portion size was 28 grams for tree nuts and peanuts, and 15 grams per slice of bread for peanut butter. The mean daily intake of nuts was calculated in grams, by multiplying the frequency of consumption by portion sizes. Total nut consumption consisted of peanut and tree nut intake. The personnel that were involved in entry, coding, and interpretation of the questionnaire were blinded to the case/subcohort status of the participations.

\section{Statistical analysis}

Cox proportional hazard models were used to estimate hazard ratios (HRs) and 95\% CIs. The consumption of total nuts, tree nuts, peanuts, and peanut butter were analysed separately, both 
on a categorical and continuous scale. Categories were divided as follows: $0,0.1-<5,5-<10$, and $10+\mathrm{g} /$ day for total nuts and peanuts, and $0,0.1-<5$, and $5+\mathrm{g} /$ day for tree nuts and peanut butter. The intake category of $0 \mathrm{~g} /$ day was used as reference group. The median value of nut consumption per category in the subcohort was used as a continuous variable in a Cox regression model to assess linear trends. For the continuous analyses, results were expressed in HRs per $5 \mathrm{~g}$ /day increment. All analyses were performed for total, non-advanced, and advanced prostate cancer, and Wald tests were performed to evaluate the statistical significance.

To control for the additional variance introduced by using the person-years at risk from the subcohort, a Huber-White sandwich estimator was used to calculate standard errors ${ }^{29}$. The proportional hazards assumption was tested with the scaled Schoenfeld residuals, -log-log survival plots, and time-covariate interaction terms. No violation of this assumption was observed for the exposure variables. Time-varying covariates were included in the model if the assumption was violated for confounders.

Factors that are known or hypothesized to be associated with prostate cancer and nut intake based on literature were assessed as confounders. Predefined confounders were included in the final model irrespective of their effect on the estimates, and include: age (years; continuous), family history of prostate cancer (yes/no), alcohol consumption (g/day; continuous), level of education (primary school or lower vocational education (low)/secondary school or medium vocational education (medium)/university or higher vocational education (high)), BMI $\left(<18.5 / 18.5-<25 / 25-<30 / \geq 30 \mathrm{~kg} / \mathrm{m}^{2}\right)$, and total energy intake (kcal/day; continuous). Potential confounders include: height ( $\mathrm{cm}$; continuous), nonoccupational physical activity $(\leq 30 />30-\leq 60 />60-\leq 90 />90 \mathrm{~min} /$ day $)$, cigarette smoking status 
(never/former/current), cigarette smoking frequency (n/day; continuous centred), cigarette smoking duration (years; continuous centred), history of diabetes (yes/no), nutritional supplement use (yes/no), tea consumption $(<1$ times per week $/ 1-<2$ times per week/2- $<4$ times per week/4- $<5$ times per week $/ \geq 5$ times per week), intake of fruit (g/day; continuous), and intake of vegetables (g/day; continuous). Potential confounders were included if the variable changed the HR by at least $10 \%$ when using a backward stepwise selection procedure. In the final multivariable-adjusted model, only the predefined confounders were included.

For the interaction analysis, the following predefined strata were considered: family history of prostate cancer (yes/no), baseline BMI $\left(18.5-<25 / \geq 25 \mathrm{~kg} / \mathrm{m}^{2}\right)$, alcohol consumption $(0 / 0.1$ $<15 / \geq 15 \mathrm{~g} /$ day), and educational level (low/medium/high). To test for interactions, crossproduct terms were included in the Cox regression models, and Wald tests were performed. Participants with a BMI $<18.5 \mathrm{~kg} / \mathrm{m}^{2}$ were deleted from the interaction analysis to increase statistical power.

The analysis was repeated with the first 2 years of follow-up excluded to assess whether preclinical disease influenced the observed associations. Besides, all nut and peanut butter consumers were excluded from the reference group to assess whether this would substantially change the results. Lastly, the analyses were repeated with mutual adjustment for the effects of other nut groups.

Statistical analysis were performed using Stata software (Version 15.0; Stata Corporation, College Station, TX), and differences were considered statistically significant at $\mathrm{P}<0.05$ for two-sided testing. 


\section{Results}

The mean consumption (SD) of total nuts, tree nuts, peanuts, and peanut butter in the male subcohort was 7.8 (13.8), 1.0 (3.3), 6.8 (13.1), and 1.4 (4.1) g/day, respectively. Baseline characteristics are presented in Table 1. As compared to the subcohort, total prostate cancer cases more often had a family history of prostate cancer, less often had a history of diabetes, and they were higher educated.

Table 2 presents the age- and multivariable-adjusted HRs for total, advanced, and nonadvanced prostate cancer according to total nut, tree nut, peanut, and peanut butter consumption. In the age-adjusted model, no significant associations were observed for the highest versus the lowest intake category of total nuts, tree nuts, and peanuts in total, advanced, and non-advanced prostate cancer cases. Peanut butter intake was associated with a statistically significant increased risk of non-advanced prostate cancer, but not with total or advanced prostate cancer. The addition of covariates to the multivariable-adjusted model slightly attenuated the HRs as compared to the age-adjusted model. In the multivariableadjusted analysis of total prostate cancer, no significant association was found for total nuts $\left(\mathrm{HR}(95 \% \mathrm{CI})\right.$ for $10+\mathrm{g} /$ day vs. non-consumers $\left.=1.09(0.92-1.29), \mathrm{P}_{\text {trend }}=0.409\right)$. Also no significant associations were found for tree nuts, peanuts, or peanut butter in total prostate cancer cases. In advanced prostate cancer cases, no significant association was found for total nuts $\left(\mathrm{HR}(95 \% \mathrm{CI})\right.$ for $10+\mathrm{g} /$ day vs. non-consumers $\left.=1.07(0.87-1.33), \mathrm{P}_{\text {trend }}=0.650\right)$, and also not for tree nut, peanut, or peanut butter consumption. In non-advanced prostate cancer cases, no significant association was found for total nuts (HR $(95 \% \mathrm{CI})$ for $10+\mathrm{g}$ /day vs. nonconsumers $\left.=1.12(0.93-1.35), \mathrm{P}_{\text {trend }}=0.341\right)$, or for tree nuts or peanuts. However, peanut butter consumption was significantly associated with an increased risk of non-advanced 
prostate cancer in the multivariable-adjusted analysis $(\mathrm{HR}(95 \% \mathrm{CI})$ for $5+\mathrm{g} /$ day vs. nonconsumers $\left.=1.33(1.08-1.63), \mathrm{P}_{\text {trend }}=0.008\right)$, and in the continuous analysis $(\mathrm{HR}$ per $5 \mathrm{~g} / \mathrm{day}$ increment $(95 \% \mathrm{CI})=1.09(1.01-1.17))$.

The associations between total nut consumption and total prostate cancer risk in strata of potential effect modifiers are presented in Table 3 . The intake categories $5-<10 \mathrm{~g} /$ day and $10+$ g/day were merged to increase statistical power. No significant interactions were observed for family history of prostate cancer, BMI, alcohol consumption, and level of education in the analyses for total (Table 3), advanced, and non-advanced prostate cancer (data not shown). Besides, no interactions were observed for peanut butter in non-advanced prostate cancer cases (data not shown). In a sensitivity analysis, exclusion of the first two years of follow-up, exclusion of all nut and peanut butter consumers from the reference group, or mutual adjustment for the effects of other nut groups, did not importantly change the results (data not shown).

\section{Discussion}

We observed no significant associations between total nut, tree nut, and peanut consumption and total, advanced, and non-advanced prostate cancer risk. No association was observed for peanut butter in total and advanced prostate cancer cases, but higher intake of peanut butter was associated with a significantly increased risk of non-advanced prostate cancer. No significant interactions with potential effect modifiers were observed with total nut consumption in total, advanced, and non-advanced prostate cancer cases.

To our knowledge, two cohort studies ${ }^{20,21}$ and three case-control studies ${ }^{22-24}$ have examined the association between nut consumption and prostate cancer risk. The large prospective 
Health Professionals Follow-Up Study and the Adventists Health Study both reported no significant associations between total nut consumption and total prostate cancer risk ${ }^{20,21}$. Thus, cohort studies consistently show no association between nut intake and prostate cancer risk, which is in line with our study. One case-control study also demonstrated no significant association between total nut consumption and total prostate cancer risk $^{22}$. In contrast, two case-control studies demonstrated significantly decreased risks for total prostate cancer ${ }^{23,24}$. A random-effects meta-analysis (including one cohort study and four case-control studies; of which three studies have been mentioned above) demonstrated a decreased risk of total prostate cancer, albeit not statistically significant ${ }^{16}$. Two case-control studies that were included in the meta-analysis, but are not mentioned above, used different reference categories as they compared different diets, and combined the intake of nuts with different food groups. There are several limitations to this meta-analysis, including a high heterogeneity $\left(\mathrm{I}^{2}=59.7 \%\right)$ and the inclusion of case-control studies that are possibly prone to recall bias and selection bias. To our knowledge, no study has examined the differential effects of tree nuts, peanuts, and peanut butter.

Only two studies have examined the differential effects of total nut consumption on total prostate cancer and advanced prostate cancer. One case-control study demonstrated no significant association for aggressive prostate cancer ${ }^{22}$. The prospective Health Professionals Follow-up Study found no significant association for advanced prostate cancer and total nut consumption $^{20}$, which is consistent with our findings.

The increased risk of non-advanced prostate cancer for increased intake of peanut butter in our study is unexpected, as it is in contrast with the hypothesis that advanced prostate cancer cases have stronger associations with etiological factors. Furthermore, it is remarkable that an 
association was found for peanut butter consumption and not for peanut consumption. Additional analysis of lifestyle differences between consumers and non-consumers of peanut butter in the subcohort did not indicate the potential for residual confounding (data not shown). Although we acknowledge that our estimates might be a result of chance findings, we tried to elucidate the mechanisms underlying the association. In 1986, in the year of exposure measurement, peanut butter contained more partially hydrogenated fatty acids (trans-fats) as compared to peanuts ${ }^{15,30}$. Several studies have indicated that trans-fatty acid markers are associated with an increased prostate cancer risk $^{31}$. The intake of trans-fats increases systematic inflammation and insulin resistance, which both have been associated with prostate carcinogenesis $^{31}$. The Physician's Health Study demonstrated that high blood concentrations of trans-fatty acids were unrelated to total or aggressive prostate cancer risk, but were associated with an increased risk of non-aggressive prostate tumors ${ }^{31}$. The SELECT study demonstrated that high blood levels of trans-fatty acids were associated with a reduced, albeit non-significant risk of high-grade prostate cancer, while a non-significant increased risk of low-grade prostate cancer was demonstrated ${ }^{32}$. The specific mechanisms explaining why peanut butter increases the risk of non-advanced prostate cancer remain unclear. As our observations alternatively might be a result of chance findings, no firm conclusions can yet be drawn.

Strengths of the current study are the prospective design and the long follow-up with excellent retention. The potential for selection bias and information bias is therefore limited. Cases with inconsistent or incomplete dietary data, or cases with missing data on confounding variables were excluded from analysis, which might have introduced selection bias if the data was not missing completely at random. Furthermore, information bias might have been introduced because of self-reported baseline measurement. As exposure and confounders were only 
measured at baseline, exposure trends over time could not be detected, which might have introduced measurement error. We have no data on tree nut subtypes, and thus tree nuts were analysed as one group. Because not all tree nuts are comparable in nutritional composition ${ }^{33}$, future studies should investigate the effect of specific types of tree nuts on the risk of prostate cancer.

In conclusion, we have demonstrated that the consumption of total nuts, tree nuts, and peanuts is not significantly associated with total, advanced, and non-advanced prostate cancer risk. However, peanut butter intake might be associated with an increased non-advanced prostate cancer risk. Further research is imperative to resolve the relation of peanut butter and nonadvanced prostate cancer, and to determine the risk-benefit trade-offs associated with dietary intake of peanut butter.

Acknowledgements: The authors would like to thank the participants of the Netherlands Cohort Study (NLCS), the Netherlands Cancer Registry, and the Dutch Pathology Registry. Furthermore, NLCS staff members are acknowledged for their valuable assistance and advice.

Conflict of interest: The authors declare no conflicts of interest

\section{References}

1. Ferlay J, Soerjomataram I, Dikshit R, Eser S, Mathers C, Rebelo M et al. Cancer incidence and mortality worldwide: sources, methods and major patterns in GLOBOCAN 2012. International Journal of Cancer 2015; 136(5): E359-E386.

2. Giovannucci E, Liu Y, Platz EA, Stampfer MJ, Willett WC. Risk factors for prostate cancer incidence and progression in the health professionals follow up study. International Journal of Cancer 2007; 121(7): 1571-1578.

3. Leitzmann MF, Rohrmann S. Risk factors for the onset of prostatic cancer: age, location, and behavioral correlates. Clinical Epidemiology 2012; 4: 1. 
4. WCRF. Diet, nutrition, physcial activity and prostate cancer., 2014.

5. Bansal D, Bhansali A, Kapil G, Undela K, Tiwari P. Type 2 diabetes and risk of prostate cancer: a meta-analysis of observational studies. Prostate Cancer and Prostatic Diseases 2013; 16(2): 151.

6. Rota M, Scotti L, Turati F, Tramacere I, Islami F, Bellocco R et al. Alcohol consumption and prostate cancer risk: a meta-analysis of the dose-risk relation. European Journal of Cancer Prevention 2012; 21(4): 350-359.

7. Huncharek M, Haddock KS, Reid R, Kupelnick B. Smoking as a risk factor for prostate cancer: a meta-analysis of 24 prospective cohort studies. American Journal of Public Health 2010; 100(4): 693-701.

8. Chan JM, Stampfer MJ, Giovannucci, gt EL. What causes prostate cancer? A brief summary of the epidemiology. Seminars in Cancer Biology 1998; 8(4): 263-273.

9. Hurst R, Hooper L, Norat T, Lau R, Aune D, Greenwood DC et al. Selenium and prostate cancer: systematic review and meta-analysis-. The American Journal of Clinical Nutrition 2012; 96(1): 111-122.

10. Geybels MS, Neuhouser ML, Stanford JL. Associations of tea and coffee consumption with prostate cancer risk. Cancer Causes \& Control 2013; 24(5): 941-948.

11. MacInnis RJ, English DR. Body size and composition and prostate cancer risk: systematic review and meta-regression analysis. Cancer Causes \& Control 2006; 17(8): 9891003.

12. Liu Y, Hu F, Li D, Wang F, Zhu L, Chen W et al. Does physical activity reduce the risk of prostate cancer? A systematic review and meta-analysis. European Urology 2011; 60(5): 1029-1044.

13. Geybels MS, Verhage BA, Arts IC, Van Schooten FJ, Goldbohm RA, Van Den Brandt PA. Dietary flavonoid intake, black tea consumption, and risk of overall and advanced stage prostate cancer. American Journal of Epidemiology 2013; 177(12): 1388-1398.

14. WCRF. Diet, nutrition, physcial activity and Cancer: a Global Perspective. A summary of the Third Expert Report. , 2018.

15. van den Brandt PA, Schouten LJ. Relationship of tree nut, peanut and peanut butter intake with total and cause-specific mortality: a cohort study and meta-analysis. International Journal of Epidemiology 2015; 44(3): 1038-1049. 
16. Wu L, Wang Z, Zhu J, Murad AL, Prokop LJ, Murad MH. Nut consumption and risk of cancer and type 2 diabetes: a systematic review and meta-analysis. Nutrition Reviews 2015; 73(7): 409-425.

17. Grosso G, Yang J, Marventano S, Micek A, Galvano F, Kales SN. Nut consumption on all-cause, cardiovascular, and cancer mortality risk: a systematic review and meta-analysis of epidemiologic studies-. The American Journal of Clinical Nutrition 2015; 101(4): 783793.

18. Richman EL, Kenfield SA, Chavarro JE, Stampfer MJ, Giovannucci EL, Willett WC et al. Fat intake after diagnosis and risk of lethal prostate cancer and all-cause mortality. JAMA Internal Medicine 2013; 173(14): 1318-1326.

19. Hshieh TT, Petrone AB, Gaziano JM, Djoussé L. Nut consumption and risk of mortality in the Physicians' Health Study. The American Journal of Clinical Nutrition 2014; 101(2): 407-412.

20. Wang W, Yang M, Kenfield SA, Hu FB, Stampfer MJ, Willett WC et al. Nut consumption and prostate cancer risk and mortality. British Journal of Cancer 2016; 115(3): 371.

21. Mills PK, Beeson WL, Phillips RL, Fraser GE. Cohort study of diet, lifestyle, and prostate cancer in Adventist men. Cancer 1989; 64(3): 598-604.

22. Pascual-Geler M, Urquiza-Salvat N, Cozar JM, Robles-Fernandez I, Rivas A, Martinez-Gonzalez LJ et al. The influence of nutritional factors on prostate cancer incidence and aggressiveness. The Aging Male 2018; 21(1): 31-39.

23. Raimondi S, Mabrouk JB, Shatenstein B, Maisonneuve P, Ghadirian P. Diet and prostate cancer risk with specific focus on dairy products and dietary calcium: a case-control study. The Prostate 2010; 70(10): 1054-1065.

24. Jain MG, Hislop GT, Howe GR, Ghadirian P. Plant foods, antioxidants, and prostate cancer risk: findings from case-control studies in Canada. Nutrition and Cancer 1999; 34(2): 173-184.

25. van den Brandt PA, Goldbohm RA, Van 'T Veer P, Volovics A, Hermus RJJ, Sturmans F. A large-scale prospective cohort study on diet and cancer in the Netherlands. Journal of Clinical Epidemiology 1990; 43(3): 285-295.

26. van den Brandt PA, Schouten LJ, Goldbohm RA, Dorant E, Hunen PMH. Development of a record linkage protocol for use in the Dutch Cancer Registry for Epidemiological Research. International Journal of Epidemiology 1990; 19(3): 553-558. 
27. Goldbohm RA, van den Brandt PA, Dorant E. Estimation of the coverage of Dutch municipalities by cancer registries and PALGA based on hospital discharge data. 1994.

28. Goldbohm RA, van den Brandt PA, Brants HA, van't Veer P, Al M, Sturmans F et al. Validation of a dietary questionnaire used in a large-scale prospective cohort study on diet and cancer. European Journal of Clinical Nutrition 1994; 48(4): 253-265.

29. Lin DY, Wei L-J. The robust inference for the Cox proportional hazards model. Journal of the American Statistical Association 1989; 84(408): 1074-1078.

30. NEVO-table: Dutch Food Composition Table 1986-1987, Nederlands voedingsstoffenbestand. Voorlichtingsbureau voor de Voeding: The Hague, The Netherlands.

31. Chavarro JE, Stampfer MJ, Campos H, Kurth T, Willett WC, Ma J. A prospective study of trans-fatty acid levels in blood and risk of prostate cancer. Cancer Epidemiology and Prevention Biomarkers 2008; 17(1): 95-101.

32. Brasky TM, Darke AK, Song X, Tangen CM, Goodman PJ, Thompson IM et al. Plasma phospholipid fatty acids and prostate cancer risk in the SELECT trial. Journal of the National Cancer Institute 2013; 105(15): 1132-1141.

33. Alasalvar C, Shahidi F. Tree nuts: composition, phytochemicals, and health effects. CRC Press, 2008. 


\section{Figure legends}

Figure 1. Flow diagram of included cases and subcohort member 


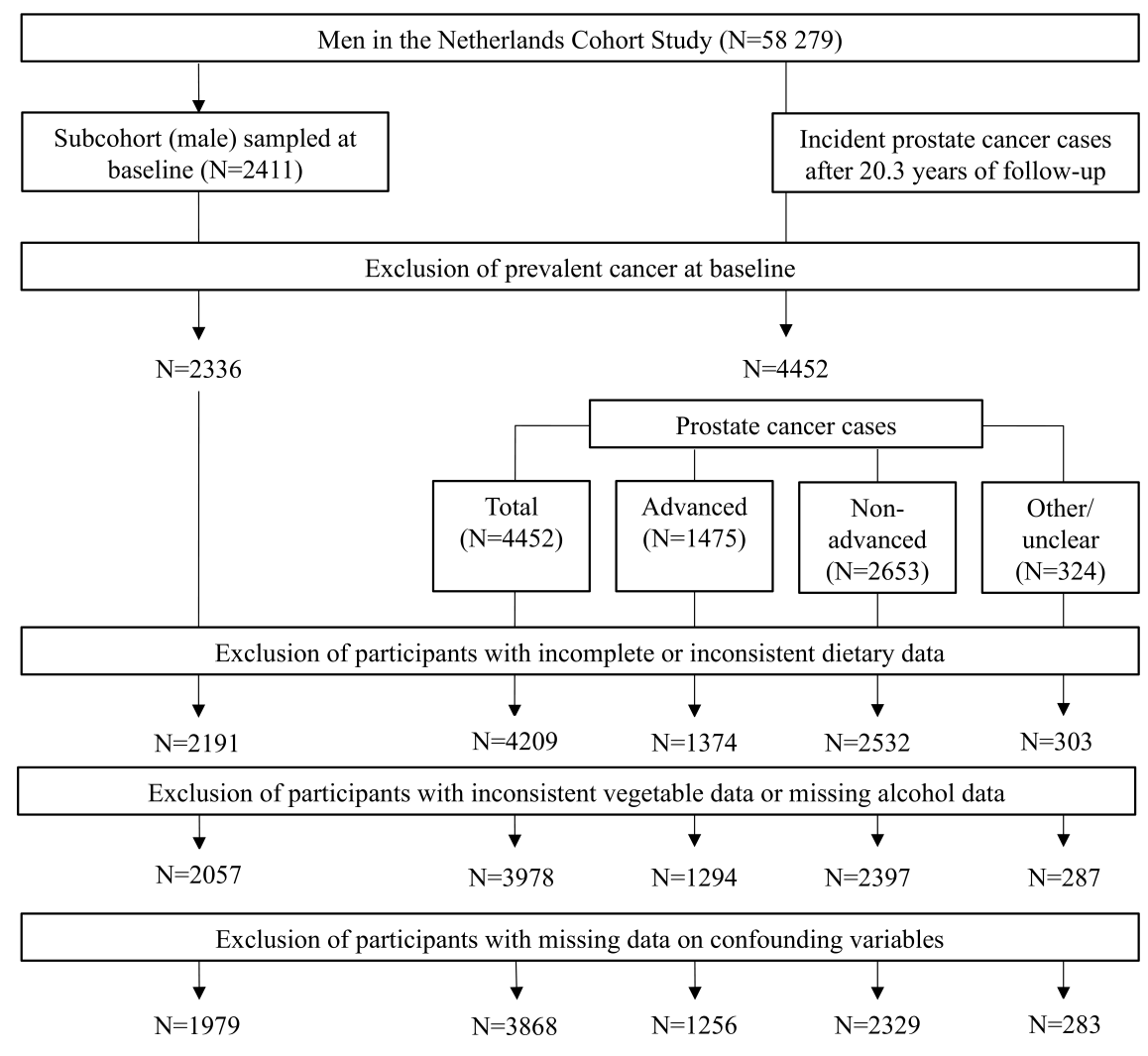


Table 1. Baseline characteristics (mean (SD) or percentage) of subcohort members and prostate cancer cases from the Netherlands Cohort Study, 1986-2006

\begin{tabular}{|c|c|c|c|c|}
\hline & \multirow[t]{2}{*}{ Subcohort } & \multicolumn{3}{|c|}{ Prostate cancer } \\
\hline & & Total & Advanced & Non-advanced \\
\hline $\mathrm{N}^{*}$ & 1979 & 3868 & 1256 & 2329 \\
\hline Age (years) & $61.3(4.2)$ & $61.8(4.1)$ & $61.7(4.1)$ & $61.6(4.1)$ \\
\hline Height $(\mathrm{cm})$ & $176.5(6.6)$ & $176.6(6.7)$ & $176.5(6.4)$ & $176.8(6.8)$ \\
\hline BMI $\left(\mathrm{kg} / \mathrm{m}^{2}\right)$ & $24.9(2.6)$ & $25.0(2.5)$ & $25.0(2.5)$ & $24.9(2.5)$ \\
\hline $\begin{array}{l}\text { Non-occupational physical activity } \\
\text { (min/day) }\end{array}$ & $80.8(67.7)$ & $79.9(61.9)$ & $77.9(59.9)$ & $80.7(62.9)$ \\
\hline Ever smokers $(\%)$ & 87.2 & 85.5 & 85.9 & 85.1 \\
\hline Higher vocational school or university (\%) & 19.7 & 23.0 & 20.8 & 24.6 \\
\hline Family history of prostate cancer $(\%)$ & 2.4 & 3.5 & 3.3 & 3.7 \\
\hline History of diabetes $(\%)$ & 3.2 & 2.7 & 2.8 & 2.7 \\
\hline \multicolumn{5}{|l|}{ Dietary intake } \\
\hline Intake of total nuts (g/day) & $7.8(13.8)$ & $8.3(15.2)$ & $8.5(16.5)$ & $8.3(14.6)$ \\
\hline Intake of tree nuts (g/day) & $1.0(3.3)$ & $1.1(3.8)$ & $1.1(3.9)$ & $1.1(3.7)$ \\
\hline Intake of peanuts (g/day) & $6.8(13.1)$ & $7.1(14.1)$ & $7.4(15.6)$ & $7.1(13.3)$ \\
\hline Intake of peanut butter (g/day) & $1.4(4.1)$ & $1.6(4.4)$ & $1.5(4.2)$ & $1.8(4.7)$ \\
\hline Total energy intake (kcal/day) & $2166(498)$ & $2159(487)$ & $2169(493)$ & $2164(482)$ \\
\hline Alcohol consumption (g/day) & $15.1(17.0)$ & $14.9(15.6)$ & $14.8(15.3)$ & $14.9(15.6)$ \\
\hline Tea consumption $\geq 2$ cups/day $(\%)$ & 68.5 & 69.4 & 67.2 & 70.2 \\
\hline Intake of fruit (g/day) & $154.8(114.4)$ & $161.5(111.8)$ & $157.1(109.7)$ & $164.8(112.6)$ \\
\hline Intake of vegetables (g/day) & $186.5(75.6)$ & $188.8(73.4)$ & $190.1(75.7)$ & $188.7(72.3)$ \\
\hline Nutritional supplement user (\%) & 23.2 & 23.9 & 22.8 & 24.3 \\
\hline
\end{tabular}

* excluding participants with prevalent cancer (except for skin cancer) at baseline, incomplete or inconsistent dietary data, or missing data on confounding variables (age, family history of prostate cancer, level of education, energy intake, alcohol consumption, and body mass index) 
Table 2. Age- and multivariable-adjusted HRs $(95 \% \mathrm{CI})$ for total, advanced, and non-advanced prostate cancer according to nut consumption, the Netherlands Cohort Study, 1986-2006

\begin{tabular}{|c|c|c|c|c|c|c|c|c|c|c|c|}
\hline \multirow[b]{2}{*}{$\begin{array}{l}\text { Food item } \\
\text { (g/day) }\end{array}$} & \multirow[b]{2}{*}{$\begin{array}{l}\text { Median } \\
\text { intake }^{a}\end{array}$} & \multirow[b]{2}{*}{$\begin{array}{l}\text { Person } \\
\text {-years }^{b}\end{array}$} & \multicolumn{3}{|c|}{ Total prostate cancer } & \multicolumn{3}{|c|}{ Advanced prostate cancer } & \multicolumn{3}{|c|}{ Non-advanced prostate cancer } \\
\hline & & & Cases & $\begin{array}{l}\text { Age-adjusted } \\
\text { HR (95\%CI) }\end{array}$ & $\begin{array}{l}\text { Multivariable- } \\
\text { adjusted HR } \\
(95 \% \mathrm{CI})^{\mathrm{c}}\end{array}$ & Cases & $\begin{array}{l}\text { Age-adjusted } \\
\text { HR (95\%CI) }\end{array}$ & $\begin{array}{l}\text { Multivariable- } \\
\text { adjusted HR } \\
(95 \% \mathrm{CI})^{\mathrm{c}}\end{array}$ & Cases & $\begin{array}{l}\text { Age-adjusted } \\
\text { HR (95\%CI) }\end{array}$ & $\begin{array}{l}\text { Multivariable- } \\
\text { adjusted HR } \\
(95 \% \mathrm{CI})^{\mathrm{c}}\end{array}$ \\
\hline \multicolumn{12}{|l|}{ Total nuts } \\
\hline 0 & 0.0 & 9393 & 1141 & 1.00 (ref) & 1.00 (ref) & 377 & 1.00 (ref) & 1.00 (ref) & 662 & 1.00 (ref) & 1.00 (ref) \\
\hline $0.1-<5$ & 2.5 & 10023 & 1291 & $1.08(0.93-1.25)$ & $1.05(0.91-1.22)$ & 424 & $1.08(0.89-1.30)$ & $1.05(0.87-1.27)$ & 777 & $1.11(0.95-1.31)$ & $1.08(0.91-1.27)$ \\
\hline $5-<10$ & 8.5 & 4148 & 503 & $1.03(0.85-1.25)$ & $0.99(0.81-1.20)$ & 150 & $0.93(0.73-1.20)$ & $0.89(0.69-1.15)$ & 323 & $1.12(0.91-1.38)$ & $1.07(0.86-1.33)$ \\
\hline $10+$ & 21.4 & 7252 & 933 & $1.13(0.96-1.32)$ & $1.09(0.92-1.29)$ & 305 & $1.11(0.91-1.36)$ & $1.07(0.87-1.33)$ & 567 & $1.16(0.97-1.38)$ & $1.12(0.93-1.35)$ \\
\hline P-trend & & & & 0.244 & 0.409 & & 0.435 & 0.650 & & 0.185 & 0.341 \\
\hline $\begin{array}{l}\text { Continuous } \\
\text { per } 5 \mathrm{~g} / \text { day }\end{array}$ & & & & $1.01(0.99-1.03)$ & $1.01(0.98-1.03)$ & & $1.01(0.99-1.04)$ & $1.01(0.98-1.04)$ & & $1.01(0.98-1.03)$ & $1.00(0.98-1.03)$ \\
\hline \multicolumn{12}{|l|}{ Tree nuts } \\
\hline 0 & 0.0 & 22309 & 2773 & 1.00 (ref) & 1.00 (ref) & 912 & 1.00 (ref) & 1.00 (ref) & 1655 & 1.00 (ref) & 1.00 (ref) \\
\hline $0.1-<5$ & 1.6 & 6963 & 886 & $1.04(0.90-1.20)$ & $1.00(0.87-1.16)$ & 284 & $1.02(0.85-1.21)$ & $1.00(0.84-1.20)$ & 539 & $1.05(0.90-1.23)$ & $1.00(0.85-1.17)$ \\
\hline $5+$ & 8.6 & 1544 & 209 & $1.11(0.85-1.45)$ & $1.10(0.84-1.44)$ & 60 & $0.97(0.69-1.37)$ & $0.97(0.68-1.37)$ & 135 & $1.19(0.89-1.58)$ & $1.17(0.88-1.57)$ \\
\hline P-trend & & & & 0.402 & 0.503 & & 0.910 & 0.860 & & 0.211 & 0.308 \\
\hline $\begin{array}{l}\text { Continuous } \\
\text { per } 5 \mathrm{~g} / \text { day }\end{array}$ & & & & $1.03(0.95-1.13)$ & $1.01(0.93-1.11)$ & & $1.02(0.92-1.14)$ & $1.01(0.90-1.13)$ & & $1.04(0.95-1.14)$ & $1.01(0.92-1.11)$ \\
\hline \multicolumn{12}{|l|}{ Peanuts } \\
\hline 0 & 0 & 10550 & 1281 & 1.00 (ref) & 1.00 (ref) & 414 & 1.00 (ref) & 1.00 (ref) & 751 & 1.00 (ref) & 1.00 (ref) \\
\hline $0.1-<5$ & 2.5 & 10952 & 1407 & $1.10(0.96-1.26)$ & $1.07(0.93-1.23)$ & 460 & $1.11(0.93-1.33)$ & $1.08(0.90-1.30)$ & 855 & $1.12(0.96-1.31)$ & $1.09(0.93-1.28)$ \\
\hline $5-<10$ & 8.5 & 3362 & 415 & $1.10(0.89-1.35)$ & $1.06(0.86-1.31)$ & 131 & $1.07(0.83-1.39)$ & $1.03(0.79-1.35)$ & 260 & $1.15(0.92-1.44)$ & $1.11(0.89-1.40)$ \\
\hline $10+$ & 21.4 & 5952 & 765 & $1.14(0.96-1.35)$ & $1.11(0.93-1.33)$ & 251 & $1.16(0.94-1.43)$ & $1.12(0.89-1.40)$ & 463 & $1.15(0.96-1.39)$ & $1.12(0.93-1.37)$ \\
\hline P-trend & & & & 0.219 & 0.332 & & 0.291 & 0.454 & & 0.226 & 0.352 \\
\hline $\begin{array}{l}\text { Continuous } \\
\text { per } 5 \mathrm{~g} / \text { day }\end{array}$ & & & & $1.01(0.99-1.03)$ & $1.01(0.98-1.03)$ & & $1.01(0.99-1.04)$ & $1.01(0.98-1.04)$ & & $1.00(0.98-1.03)$ & $1.00(0.98-1.03)$ \\
\hline \multicolumn{12}{|l|}{$\begin{array}{l}\text { Peanut } \\
\text { butter }\end{array}$} \\
\hline 0 & 0.0 & 22148 & 2695 & 1.00 (ref) & 1.00 (ref) & 885 & 1.00 (ref) & 1.00 (ref) & 1593 & 1.00 (ref) & 1.00 (ref) \\
\hline $0.1-<5$ & 1.2 & 5290 & 701 & $1.15(0.99-1.35)$ & $1.14(0.97-1.33)$ & 229 & $1.14(0.94-1.39)$ & $1.14(0.94-1.39)$ & 424 & $1.18(0.99-1.39)$ & $1.15(0.97-1.37)$ \\
\hline $5+$ & 9.6 & 3379 & 472 & $1.19(0.99-1.44)$ & $1.19(0.99-1.44)$ & 142 & $1.09(0.86-1.38)$ & $1.08(0.85-1.38)$ & 312 & $1.33(1.08-1.62)$ & $1.33(1.08-1.63)$ \\
\hline P-trend & & & & 0.071 & 0.072 & & 0.485 & 0.526 & & 0.007 & 0.008 \\
\hline $\begin{array}{l}\text { Continuous } \\
\text { per } 5 \mathrm{~g} / \text { day }\end{array}$ & & & & $1.05(0.98-1.12)$ & $1.06(0.99-1.13)$ & & $1.02(0.94-1.10)$ & $1.02(0.94-1.11)$ & & $1.08(1.00-1.15)$ & $1.09(1.01-1.17)$ \\
\hline
\end{tabular}

$\frac{\text { per } 5 \mathrm{~g} / \text { day }}{{ }^{\mathrm{a}} \text { Median intake in the subcohort }{ }^{\mathrm{b}} \text { Person-years in the subcohort }{ }^{\mathrm{c}} \text { Adjusted for: age (years; continuous), family history of prostate cancer (yes/no), body mass }}$ index $\left(<18.5 / 18.5-<25 / 25-<30 / 30+\mathrm{kg} / \mathrm{m}^{2}\right)$, alcohol consumption $(0 / 0.1-<5 / 5-<15 / 15-<30 / \geq 30 \mathrm{~g} /$ day), level of education (primary or lower vocational/secondary or medium vocational/university or higher vocational), and total energy intake (kcal/day; continuous) 
Table 3. Multivariable-adjusted ${ }^{\mathrm{a}}$ HRs $(95 \% \mathrm{CI})$ for total prostate cancer according to total nut consumption in subgroups, the Netherlands Cohort Study, 1986-2006

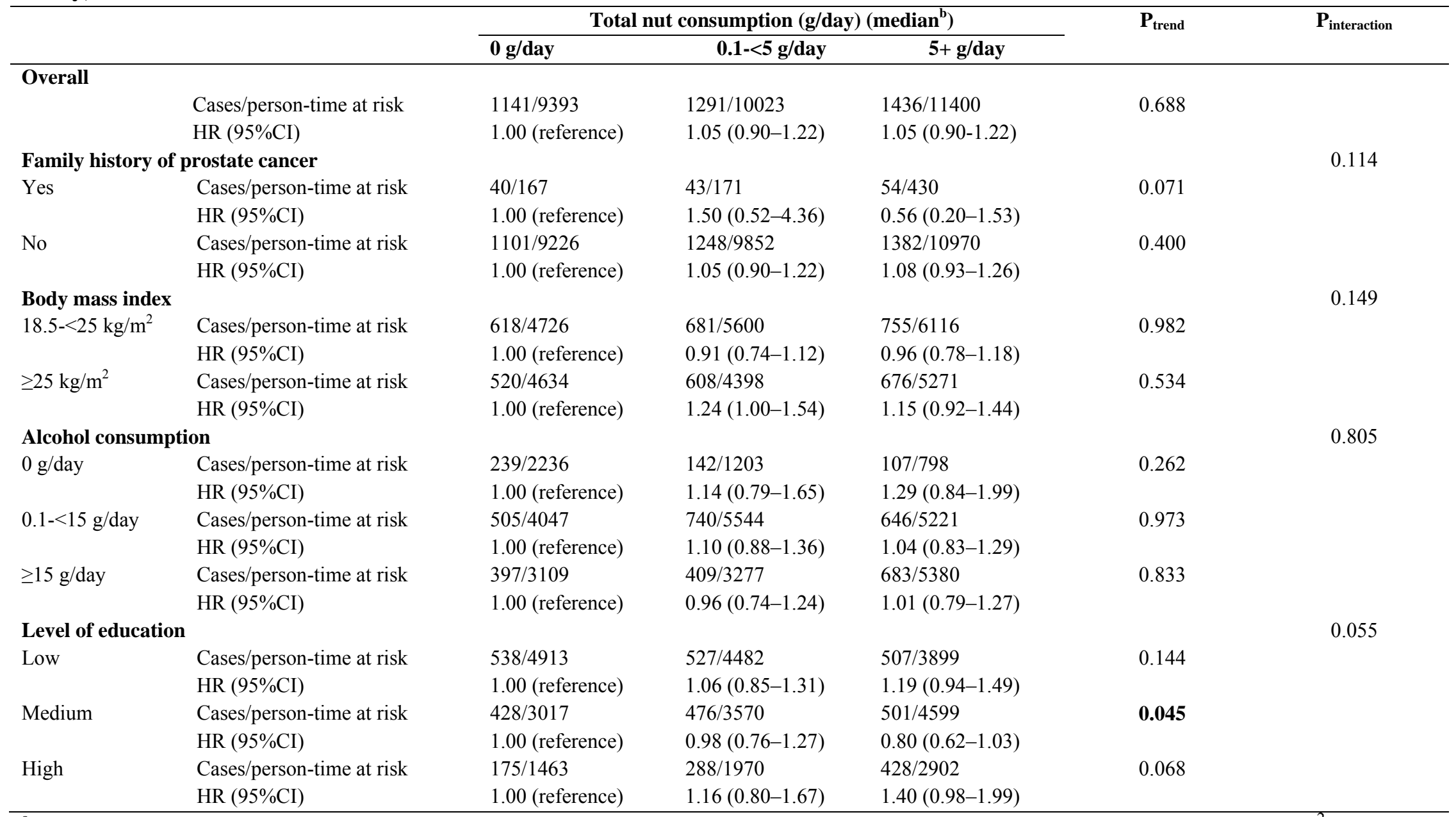

${ }^{a}$ Adjusted for: age (years; continuous), family history of prostate cancer (yes/no), body mass index $\left(18.5-<25 / 25-<30 / 30+\mathrm{kg} / \mathrm{m}^{2}\right)$, alcohol consumption $(0 / 0.1$ $<5 / 5-<15 / 15-<30 / \geq 30 \mathrm{~g} /$ day), level of education (primary or lower vocational/secondary or medium vocational/university or higher vocational), and total energy intake (kcal/day; continuous) ${ }^{\mathrm{b}}$ Median intake in the subcohort 